\title{
Redoable Tie-Over Dressing Using Multiple Loop Silk Threads
}

\author{
Hyeon Jong Jo ${ }^{1}$, Jun Sik Kim², Nam Gyun Kim², Kyung Suk Lee ${ }^{2}$, Jae Hoon Choi ${ }^{2}$ \\ ${ }^{1}$ Department of Plastic and Reconstructive Surgery, ${ }^{2}$ Institue of Health Sciences, Gyeongsang National University Hospital, Gyeongsang \\ National University School of Medicine, Jinju, Korea
}

After skin grafting, to prevent hematoma or seroma collection at the graft site, a tie-over dressing has been commonly used. However, although the conventional tie-over dressing by suture is a useful method for securing a graft site, refixation is difficult when repeated tieover dressing is needed. Therefore, we recommend a redoable tie-over dressing technique with multiple loops threads and connecting silk threads. After the raw surface of each of our cases was covered with a skin graft, multiple loop silk thread attached with nylon at the skin graft margin. We applied the ointment gauze and wet cotton/fluffy gauze over the skin graft, then fixed the dressing by connecting cross-counter multiple loop thread with connecting silk threads. When we opened the tie-over dressing by cutting the connecting silk threads, we repeated the tie-over dressing with the same method. The skin graft was taken successfully without hematoma or seroma collection or any other complications. In conclusion, we report a novel tie-over dressing enabling simple fixation of the dressing to maintain proper tension for wounds that require repetitive fixation. Further, with this reliable method, the skin grafts were well taken.

Keywords Skin transplantation / Reconstructive surgical procedure / Surgical fixation devices
Correspondence: Kyung Suk Lee Institute of Health Sciences, Gyeongsang National University Hospital, Gyeongsang National University School of Medicine, 79 Gangnam-ro, Jinju 660-702, Korea Tel: $+82-55-750-8133$

Fax: +82-55-758-6240

E-mail: opensound@hanmail.net

Received: 5 Feb 2013 • Revised: 6 Feb 2013 • Accepted: 8 Feb 2013

pISSN: 2234-6163 • elSSN: 2234-6171 • http://dx.doi.org/10.5999/aps.2013.40.3.259 • Arch Plast Surg 2013;40:259-262

\section{INTRODUCTION}

Skin graft is the most widely and easily utilized method in the reconstruction of soft tissue defects. For a skin graft to survive on its wound bed, it must adhere well enough to allow blood vessels to grow across the gap [1]. A tie-over dressing is a widely used method for increasing the survival of the skin graft. In case of the conventional tie-over method, however, re-fixation is difficult when tie-over dressing is required repeatedly after the dressing has been opened. Therefore, we would like to introduce a method that allows easy refixation and maintaining the proper tension on skin graft sites using multiple loop silk threads.

\section{IDEA}

This article was presented at the 70th Congress of the Korean Society of Plastic and Reconstructive Surgeons on November 9-11, 2012 in Seoul, Korea.

No potential conflict of interest relevant to this article was reported.
In the new tie-over dressing method that we perform, utilizing multiple loop threads made with silk is the most distinctive difference from the conventional tie-over dressing (Fig. 1). First of all, the wound in the recipient location is debrided and then the skin for the graft is harvested. Secondly, multiple loop silk threads are fixed along with the skin graft margin using nylon. Lastly, after dressing with ointment and cotton/fluffy gauze, a tie-over dressing is performed by connecting between multiple loop threads with different silk (Fig. 2). For convenience in the selective elimination of the connecting silk when opening the 
tie-over dressing, it is better to utilize a suture of a different color than that of the multiple loop thread.

The biggest advantage of the method is that if the connecting silk between the multiple loop threads is disconnected, when the dressing is to be closed again it is possible to perform a tieover dressing just as it had been done the first time. A tie-over dressing may be performed again with removal of the connecting silk only in the following cases: the tie-over dressing should be opened earlier and more frequently than is normally sched-

\section{Fig. 1. Multiple loop silk thread}

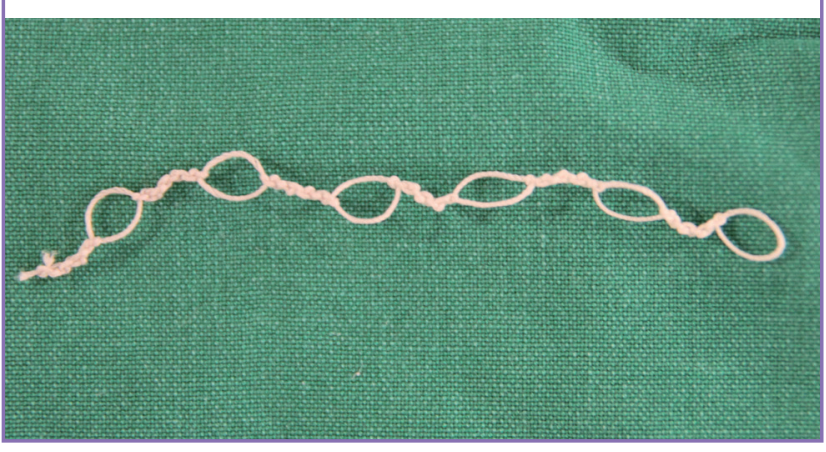

Fig. 2. Schematic of a tie-over dressing

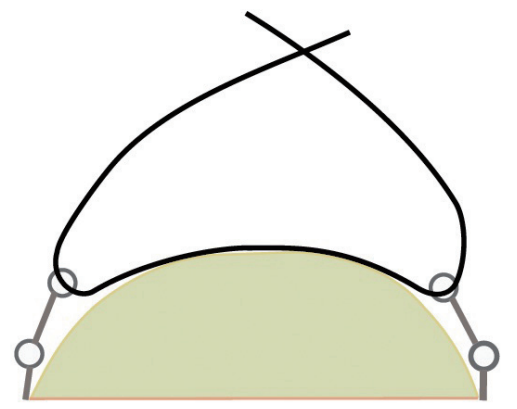

uled for patients with a history of wound infection, a bleeding tendency, or anticoagulant administration. Furthermore, a repeated tie-over dressing may be performed on curvy body areas of the buttock or trunk where the dressing is difficult to secure and on hairy sites like the scalp, thereby maintaining proper tension in skin graft sites.

\section{Case 1}

A 63-year-old female presented with the chief complaint of a mass lesion on the front of the scalp that occurred 5 years earlier and was diagnosed as basal cell carcinoma in the biopsy. After surgical excision, a skin graft was carried out by harvesting the full thickness of skin from a site. Five days after the surgery, the tie-over dressing was opened and the tie-over dressing, as described previously, was reapplied. The skin graft was well taken without other complications (Fig. 3).

\section{Case 2}

A 63-year-old male came to the hospital with skin defects in the

\section{Fig. 3. Tie-over dressing on scalp area}

A 63-year-old female with a scalp defect after surgical excision of basal cell carcinoma. Scalp defect on the front of the scalp. After full thickness skin graft, tie-over dressing performed using multiple loop thread and cross connecting silk.

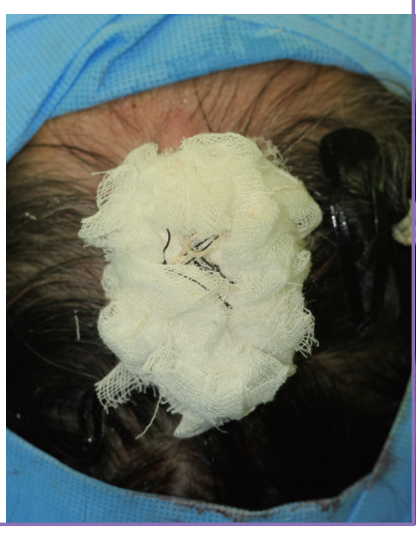

Fig. 4. Tie-over dressing to patient with bleeding tendency

A 63-year-old male with a soft tissue defect on his left pretibia area. (A) Intraoperative photographs were taken during the tie-over dressing using multiple loop thread. (B) Photo taken 10 days postoperatively.
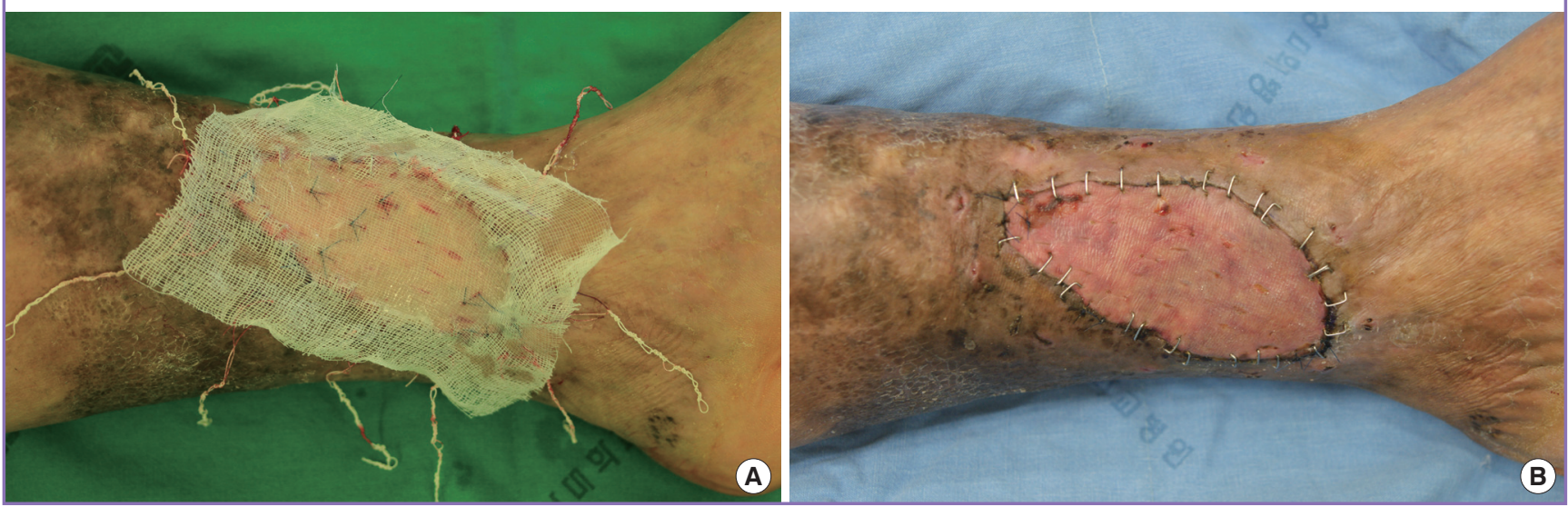
left pretibia area that had appeared a month earlier. The patient possessed underlying diseases including diabetes, hypertension, and atherosclerosis obliterans (ASO) and was administered an anti-coagulant agent for the ASO. After wound debridement was carried out, the full thickness of skin obtained from the groin was grafted at the defect sites. Based upon his drug history, the possibility of hematoma was considered, so the tie-over dressing was opened two days after the surgery. Hematoma collection was confirmed and a tie-over dressing was performed again after the removal of the hematoma collection. The tie-over dressing was performed continuously until nine days after the surgery and the skin graft was well taken (Fig. 4).

\section{Case 3}

A 56-year-old female presented to the hospital with a skin lesion on the right buttock that had appeared one year earlier. On the biopsy, the patient was diagnosed with Bowen's disease and surgical excision was carried out. After the excision, the full thickness of the skin obtained from groin sites was grafted onto the defect sites because primary closure of the surgical area was difficult. Five days after the surgery, the tie-over dressing was opened and re-tie-over dressing was applied in order to maintain proper tension in the skin graft sites even though seroma and hematoma collection were not observed. Eleven days after the

\section{Fig. 5. Tie-over dressing on buttock area}

A 56-year-old female with a soft tissue defect after surgical excision of Bowen's disease on the right buttock area. Repeated tie-over dressing on postoperative day 5 to generate even tension.

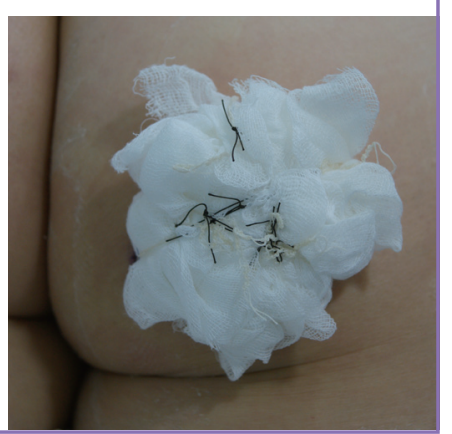

surgery, we confirmed that the graft was taken up successfully without any complications (Fig. 5).

\section{Case 4}

A 77-year-old male presented with the chief complaint of a soft tissue defect on the right knee area. The wound had a bacterial infection with methicillin-resistant Staphylococcus aureus. After treatment with intravenous antibiotics (vancomycin $1 \mathrm{~g}$ every 12 hours for 7 days) and daily wound dressing, skin grafting was carried out by harvesting a split thickness of skin from the right thigh. One day after the surgery, a large amount of serous discharge was observed through the dressing and infection was suspected. The tie-over dressing was opened and the seroma was evacuated. Tie-over dressing was performed continuously until nine days after the surgery and the skin graft was taken up successfully (Fig. 6).

\section{DISCUSSION}

In a skin graft, good postoperative care begins with the dressing. For grafts to the trunk or head and neck, a bolus or tie-over dressing can be used. The bolus dressing minimize the risk of hematoma or seroma formation and also prevents shearing forces from disrupting the graft [2].

Although tie-over dressings are widely used when performing skin grafts, the difficulty in re-fixation after the dressing has been opened is the disadvantage of a conventional tie-over dressing. Many researchers have introduced various tie-over dressing methods; of them, those that are reproducible have also been introduced [3-7].

Whereas fixation utilizing sutures such as the silk and nylon of our method is similar to the conventional tie-over dressing, our method differs from the conventional method in that repetitive tie-over dressing is possible to perform using multiple loop threads. When tie-over dressing needs to be opened in the early

Fig. 6. Soft tissue defect with bacterial infection

A 77-year-old male with a soft tissue defect in the right knee area. (A) Preoperative photo. (B) Postoperative photo taken 8 weeks after the surgery.
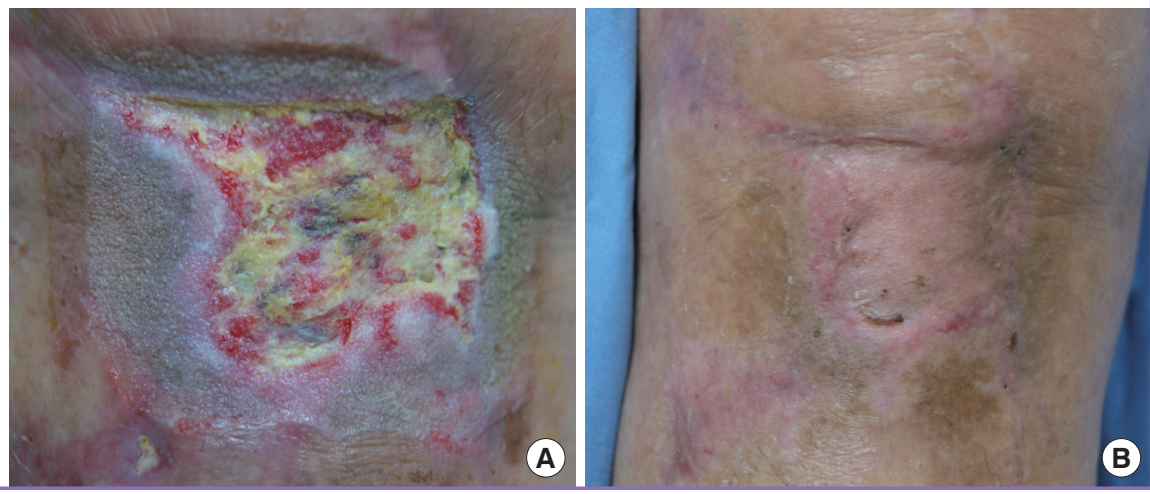
stage to examine the skin graft and then re-fixation is required in patients with infection wound or a bleeding tendency, re-fixation could be carried out on the skin graft sites as in the beginning by re-utilization of multiple loop threads. Moreover, proper tension was maintained on the skin graft sites via multiple loop threads in the curvy body areas of the buttock or trunk where dressing fixation is difficult and hairy sites like the scalp. Some authors have reported methods that utilize materials such as a bra hook with a band or a jacket clip for a reproducible tie-over dressing $[7,8]$. A tie-over dressing using a bra hook with a band may be difficult to apply to extremely large or small wounds, whereas the tie-over dressing that we introduced could be applied regardless of the size of the defect site by controlling the length of the multiple loop threads. In addition, as we used silk, a material that was easily obtained, we did not have to prepare special materials during the preparation for surgery. Although our method had the disadvantage that multiple loop thread must be fabricated, we sterilized and reused the threads that were utilized during the tie practice, thereby saving the time that would have been needed to make multiple loop threads during surgery.

In our hospital, we opened the tie-over dressing if seroma or hematoma was suspected on postoperative day one or two. Refixation could then be carried out on the skin graft sites. Following that, we conducted tie-over dressings daily or every other day until the wound was stable.

In comparing our method with hydro-occlusive dressing, the biggest advantage of our method is that areas that would otherwise be difficult to fix can be easily fixed. After removal of a hematoma or seroma, the proper pressure must be applied, and our method can provide the appropriate pressure. Hydro-occlusive dressing cannot easily absorb large amounts of exudates, and can act as a medium of bacterial infection [2]. Our method allows for the removal of exudates and the control of infection by using an open tie-over dressing in the early stage when infection is suspected.

Our method may be considered for a number of reasons: a tie-over dressing should be opened earlier and more frequently than regularly scheduled when patients have a history of wound infection, a bleeding tendency, or are receiving anticoagulants; repeated tie-over dressing may be carried out in curvy body areas of the buttock or trunk where a dressing is difficult to fix and on hairy sites like the scalp.

In conclusion, we reported a novel tie-over dressing that enables easily fixing the dressing to maintain proper tension and dressing a wound that requires repetitive fixation; further, with this reliable method, the skin grafts were taken successfully.

\section{REFERENCES}

1. Rudolph R, Ballantyne DL. Skin graft. In: McCarthy JG, editor. Plastic surgery. Philadelphia: W.B. Saunders; 1990. p.221-74.

2. Paletta CE, Pokorny JJ, Rumbolo P. Skin graf. In: Mathes SJ, editor. Plastic surgery. 2nd ed. Philadelphia: W.B. Saunders; 2006. p.873-86.

3. Thomas DG, Breslow N, Gart JJ. Trend and homogeneity analyses of proportions and life table data. Comput Biomed Res 1977; 10:373-81.

4. Valdatta L, Thione A, Buoro M, et al. The reproducible tieover dressing. Plast Reconstr Surg 2003;112:708.

5. Lee SJ, Kim YO, Park BY. A simple and rapid tie-over dressing with skin stapler and round rubber band. J Korean Soc Plast Reconstr Surg 2003;30:359-61.

6. Kim PC, Park SS, Lee YJ, et al. Easy reproducible tie-over dressing using Silastic(R) drainage. J Korean Soc Plast Reconstr Surg 2010;37:313-6.

7. Dogan F, Ozyazgan I, Eskitascoglu T. A new useful and renewable tie-over dressing method using package bands and bra hooks. Ann Plast Surg 2006;57:348-9.

8. Budi S, Rados J, Stanec Z. A sports jacket clip: a simple method of securing tie-over dressings. J Plast Reconstr Aesthet Surg 2009;62:e495-6. 